\title{
Collective Action in Implementing Top-Down Land Policy: The Case of Chengdu, China
}

\begin{abstract}
Rapid urbanization in China has led to the increasing scarcity of land suitable and available for construction. Concurrently, rural depopulation has resulted in many vacant properties, including farmhouses and buildings. In order to address this issue, a national land transfer policy has been implemented since the early 2000s in which vacant rural properties are returned to agriculture in return for similar areas of periurban land being released for construction. While there have been many different approaches to policy implementation, most commentators agree that successful schemes are characterized by the involvement of local people. As yet, however, there has been little research into how such local collective action is organized, and whether it is really possible to address top-down policies through local, bottom-up, action. Based on a case study of the earliest pilot program in Chengdu, Sichuan Province, we seek to demonstrate that the top-down nature of China's land transfer policy does not mean that it is necessarily best implemented in a top-down manner. Indeed, we suggest that effective collective action is crucial to the realization of such policies. In particular, the case study indicates that with the empowerment of villagers to participate in the policy process it is possible to achieve a broad consensus on the best approach to addressing the problems, with community interests protected and properly monitoring. In offering a new way of understanding collective action, we conclude that even in cases where a top-down approach is imposed, communities can be empowered to act collectively in implementing the policy from the bottom-up.
\end{abstract}

Key words: Collective Action; Rural Construction land; Bottom up approach; Community empowerment

\section{Introduction}

There has been rampant urbanization in China since the economic reforms of 1978 , with high economic growth, rural-urban migration and increasing demand for construction land in and around cities (see Skinner, et al, 2001; Lin and Ho, 2003;

Long et al., 2007, 2011; Fang, et al, 2016; Liu, P., et al, 2016; Qin and Liao, 2016).

This has led to considerable controversy and conflict in the allocation of land, 
particularly relating to decisions to convert agricultural land into construction land on the urban fringe (Tang, et al, 2012; Liang, et al, 2015; Jin, et al, 2016; Yep and Forrest, 2016). Not only has this changed the character of peri-urban land, but it has threatened local food supplies (Yang and Li, 2000; Chen, 2009; Zhou, 2010; Jiang, et al, 2015; Fang, et al, 2016) and has changed the culture of rural life (Friedman, 2006; Xu, et al, 2011; Siciliano, 2012; Li, et al, 2014). Indeed, as Brown and Shucksmith (2016: p.183) have commented, 'change, not stability, is the normal situation facing rural communities today.' While this is not an entirely new phenomenon, in China or elsewhere, the issues have intensified in recent years as the pace of urban expansion has increased (Xu, et al, 2011; Li, 2013; Li, et al, 2016), meaning that China is facing unprecedented questions about how it balances the many competing claims for land on the urban fringe (Long, et al, 2012).

In seeking to address this issue, the Chinese central government evolved its Redline Paradigm in the late 1990s, which involved creating an 'insurmountable boundary' around farm land to prevent the further net loss agricultural land to non-agricultural development ( $\mathrm{Lu}$, et al, 2012; He, et al., 2014; Bai, et al, 2016). This has since been modified to reflect an ecosystem services approach to land conservation (Bai, et al, 2016) which has sought to protect the overall area of crop and other lands while also demarcating restricted and prohibited development zones. At the core of this is the policy of 'Coordinating Urban and Rural Construction Land' (CURCL), which has attracted much attention in the literature (Xu, et al, 2011; Long, et al, 2012; Tang, et al, 2012; Huang, et al, 2013). It was introduced by the Ministry of Land and Resources of China in 2005, with the key objective of achieving equilibrium in the supply of construction land by balancing increases in urban construction land with decreases in rural construction land (Long, et al, 2012). The policy, known colloquially as the "increasing vs. decreasing balance' land-use policy' (Long, et al, 2012: p.20) is based on the relocation of farmers' housing from the countryside to rural residential districts, while allowing the farmers to continue farming. The land upon which the former farmhouses and abandoned farmsteads stood - of which 
there is a lot (Qin and Liao, 2016) - is then reclaimed as farmland, with an area of farmland (equivalent to the reclamation area minus the farmland area occupied by the new residential district) adjacent to the city made available for conversion into urban construction land. As such, the CURCL policy is an instrument used by governments to provide construction land for economic growth while protecting arable land (Tang, et al, 2012).

Rather than being a relatively simple approach to the forced purchase of building land on the urban fringe, therefore, the CURCL policy is what Long, et al (2012: p.17) term a "spatial transfer of land development rights" in which local governments and development companies can generate large revenues from the difference between the value of these rights and the compensation paid to farmers. Given that farmer participation in the pilot scheme has been voluntary, the government has emphasized that if no agreement is reached, no programs would be initiated. Yet farmers have participated in many schemes (Liu, et al, 2016), suggesting that such schemes are likely to have been developed in the most advantageous financial locations, for the more powerful stakeholders, rather than necessarily where there is a lot of abandoned property or good land to be reclaimed.

The CURCL policy has received considerable scrutiny, in terms of its potential implications (Lu, et al, 2012) and in terms of its implementation, at this stage through pilot programs (Xu, et al, 2011; Long, et al, 2012; Tang, et al, 2012; Huang, et al, 2013). Research has found that it has been effective in reducing conflict between conservation and development (Tang, et al, 2012) and that it has contributed to the improvement of farmers' housing conditions (see Dou, et al, 2008; Long, et al, 2011; Huang, et al, 2013; Yep and Forrest, 2016). However, it is also clear that not all those involved have been equally enthusiastic, with the strongest motivation for implementing the policy coming from local government and external investors, rather than farmers (Long, et al, 2012; Tang, et al, 2012). Indeed, perhaps the greatest indictment of the policy has been the general lack of official recognition that there has 
been for the negative impact that it has had on the culture and economy of many farming households (Xu, et al, 2011; Siciliano, 2012; Tang, et al, 2012; Huang, et al, 2013; Yep and Forrest, 2016), and its wider contribution to declining local food security (Chen, 2009; Zhou, 2010; Jiang, et al, 2015).

In their work, Long, et al (2012) have argued that this lack of consideration for farmers and their neighbors has arisen because of:

... a failure to adequately engage and enroll local actors into the planning and decision-making process. Although some programs ... have involved grassroots participation, more generally the input of local people is perceived to be limited. (Long, et al, 2012: p.20)

While similar conclusions have been drawn in other research (Tang, et al, 2012), and calls have been made for public participation to be brought into the operation of the policy (Lu, et al, 2012), there is little evidence to date about how this might happen. Our intention in this paper is to build on recent research into local collective action (Li, et al, 2016; Liu, Z. et al, 2016) in order to address this gap in the literature. Our core argument is that it is not necessarily the case that top-down policies of this nature must be implemented in a top-down manner. On the contrary, we suggest that bottom-up policy implementation informed by effective collective action are crucial to the equitable and successful realization of top-down schemes of this type. The aim of this paper is thus to examine the extent to which a top-down policy such as CURCL can be implemented from the bottom-up. In particular, we want to examine why those likely to be adversely affected are willing to become part of the policy process, what the impacts of the CURCL policy have been on them, and how these impacts have been managed by the ability of the farmers to participate in forms of collective action.

Using a case study of Lianghe Village in the south west of Chengdu City, we seek to demonstrate that with the empowerment of villagers to participate in the policy process it is possible to achieve a broad consensus on the best approach to 
addressing the problems, with community interests suitably monitored and protected. We conclude that even in cases where a top-down approach appears necessary, consideration should be given to implementing the policy from the bottom up by supporting communities to be able to take strong and collective action. The paper commences with a review of the literature on collective action, which argues that narrow western understandings are inappropriate to the situation in China, where a lack of purposive collective organization is balanced by the potential power of the convergent behaviors of many individuals. The case of Lianghe Village is then used to identify where collective action has occurred, how it has been fostered and what impact this has had on the implementation of CURCL. The final section of the paper discusses the findings and argues that the lack of local collective organization characteristic of the State monopoly of the public realm in China does not prevent individuals from asserting their needs in common with others.

\section{The Potential for Collective Action}

There is a rich literature on collective action, related in general to the ways in which people act together (Gilbert, 1989, 2006; Oliver, 1993), and with respect to the institutions through which certain common pool resources are managed (Ostrom, 1990). Notwithstanding Olson's (1965) differentiation between self-interest and the public good, collective action is conventionally understood as arising from a shared interest between a group of people (Oliver, 1993), implying the existence of social networks, freedom of action and some element of spatial connection (Bosco, 2001). This is not the collective as it is understood historically in China (Nolan, 1988), but a voluntary form of association based on the social identity and spatial proximity of those involved (see Liu and Ravenscroft 2016).

For van Zomeren, et al (2012), collective action arises from three conditions: injustice, efficacy and identity. In their research they found that there was a causal 
link between feelings of unjust deprivation and the development of collective action. This was reinforced where there were clear social identities to protect and also where it was felt that collective action was a justified means of achieving particular collective goals. As Ostrom's (1990) work has illustrated, it is this third condition - the efficacy of collective action - that has often been difficult to achieve, due to a lack of suitable institutional arrangements through which deprived and marginalized people can make their collective case. This seems to be the case with the CURCL policy, where there is little doubt that rural people - farmers in particular - are being asked to make fundamental changes in their lives with apparently little way of participating in the decision-making process. Indeed, as Tang, et al (2012: p389) have argued, the implementation of current policy means that the rights of many farmers are ' $\ldots$ seriously violated.'

Yet there is little evidence of the organized and purposive collective action typically found in such situations (Wanyama, et al, 2014). This is largely because such action is not so possible in China, where significant State control of the public sphere tends to mean that collective action occurs as a result of many individual behaviors converging in the same direction and assuming a form of collective character (Zhou, 1993: p54). This is not to say that there is a lack of potential for collective action, but that it needs to be understood in the context of rural China, where most people are tied to both the place and their social position within it. Lacking the efficacy to organize collective action against those with higher status, the collective amounts to what Zhou (1993: p56) terms a 'subordinate society' in which people have to act individually, but in a context in which their legitimate range of actions is so circumscribed that their behaviors converge (we note that Panelli, 2004, claims that this is not limited to China, but is the case in most situations). Not only can this amount to a (disorganized) form of social mobilization (termed 'rightful resistance' by O'Brien and Li, 2006), but it can actually be a powerful one because it does not depend on acquiescence and obedience to a common institutional form (Simpson and Macy, 2004). 
In addressing the potential for collective action in responding to the CURCL policy, therefore, we understand that we have to move beyond narrow western ideas of organized and effective collective action to examine how individual, subordinate, people respond in ways that offer them some collective bargaining power. This is not, therefore, research about collective action in the conventional and purposive sense, but rather an investigation into whether individually shared interests and behaviors can influence a bottom-up approach to implementing top-down policy. Our research question is: To what extent is the successful implementation of CURCL schemes dependent on legitimizing collective action?

\section{Methods and procedures}

The research question seeks insights from those involved, as individuals and group members, largely in the form of memories of events that have taken place in the last few years. It is therefore suited to a constructivist approach to data generation focused on how these participants understood and felt about the implementation of the CURCL policy. This means that the individual is of primary concern, but within a spatial and temporal context that involves interaction with other people (Lauckner, et al, 2012). This interactional focus meant also that data need to be generated from a real-world community (Yin, 2009) that had experienced the negotiations surrounding and the impacts of the policy.

A single case study method was chosen as the means of data generation. We selected Lianghe Village, located at the southern west of Chengdu City, because initial research indicated that the villagers had worked together through a form of collective action to try and secure an equitable settlement from the implementation of the CURCL policy. Lianghe Village has a population of 2115 in 618 households and 12 villager groups. The total farmland was $4676.05 \mathrm{mu}$. About $1 / 3$ of the population, 
mainly young people, work outside the county. Chengdu City was, in 2007, one of the pilot areas designated for exploring the optimization of rural construction land, meaning that it has been subject to considerable academic scrutiny (see $\mathrm{Wu}, 2011$; Long, et al, 2012; Huang, et al, 2013).

A group of four researchers undertook the local investigation for 15 days during July and August 2013, covering 10 villages (including Lianghe Village) in 4 counties (Pujiang, Jinjiang, Wenjiang, Shuangliu). In each village the interviewees included local government officials, village leaders and farmers. In the case of Lianghe Village, interviews took place with 3 government officials, and 3 group interviews were held separately: one with 2 village leaders and 3 villagers, one with 3 villagers who participated in the CURCL Program, and one with 3 villagers who did not participate.

Structured in-depth interviews were carried out using a series of open-ended questions to which the interviewees could give narrative responses. For the county and town government officials, questions were asked about the general implementation of the policy, the main operating processes, the problems or failures most frequently encountered and local solutions. The main questions for the group interviews were about their motivation to participate in the program, how the decisions of individuals (whether to participate or not, for example) and of the village leaders (such as the setting of standards for participants) were made, and how the policy was implemented. These interviewees were also asked about the main problems that they encountered and how these problems were solved. The interview records were taken down in shorthand, and written up that evening. The researchers held regular reviews to compare their findings and to make sure that nothing significant was missed out.

In addition, the leaders of Lianghe Village managed to take excellent records of all kinds of village meetings. All the records taken during the period 2011 to 2013 were made available to the researchers, which served as the main secondary data source 
for researching the process of policy implementation. The records were analyzed according to the same themes as the interviews, with significant entries copied by photo and translated into the fieldwork transcript.

\section{Findings: the role of collective action in Lianghe Village}

The program in Lianghe Village was initiated in 2010 and completed in 2013. In common with some of the other programs, it was at first run by a private investment company but encountered serious cash flow problems. As a result, the village committee decided to take over the program and implement it themselves. There was a collective sense of injustice that the company scheme had not worked, leaving them in a vulnerable position, although by the same token this gave them the efficacy to act collectively. The village committee worked hard to find suitable finance and was eventually able to make an arrangement with the Bureau of Land and Resource of Chengdu City, through a mortgage on future CURCL credits (at the benchmark price of 230,000 yuan per mu, or approx. 15,000 yuan per hectare). The program built a total area of $39,000 \mathrm{~m}^{2}$ of housing, for 293 households (1150 individuals). The

reclaimed farmland amounted to $398.4 \mathrm{mu}$ (26 hectares) and the land for building the new centralized housing was about $103 \mathrm{mu}$ (6.5 hectares). Thus the final CUCRL credits amounted to $295.5 \mathrm{mu}$ (approx. 20 hectares). About $95 \%$ of the credits were purchased via the Rural Property Rights Exchange of Chengdu, with the remaining $5 \%$ saved by the village for future development.

Like most township governments, the Lianghe village authorities had originally expected to play a relatively minor role in implementing the policy, mainly through advocating the program to villagers and farmers, helping the village organize and apply for the credits, and monitoring progress. In many ways it would have helped shape the behavior of individual villagers in ways that converged with a collective approach to the policy. In taking on the implementation themselves, however, the 
village authorities had to move away from this facilitating approach to address all the difficult issues, including determining competing claims over land. This led to the development of a new approach to collective action, achieved by revitalizing an old system, known as Yi-Shi-Hui (YSH), which had been developed in the 1980s. This involved the villagers selecting a committee of reputable elders and capable people who were tasked with working collectively to resolve conflicts. The committee was convened by the Village Secretary of the Party, who acted in a non-voting capacity. The YSH provided a strong base for collective action during the implement of the CURCL policy, a situation acknowledged by all the villagers who were interviewed.

The most obvious advantage of the $\mathrm{YSH}$ approach was in resolving the internal village disputes about land rights. Given the lack of written documents, many interviewees responded with the old Chinese saying that 'Each side is reasonable' ('Gong Shuo Gong You Li, Po Shuo Po You Li'), implying the need for a neutral forum in which claims could be aired. While it could not reduce the burden of hearing claims and counter-claims, the YSH was familiar with the local situation, the history and the current state of the land. Sometimes it took many meetings and long evenings to find resolutions, with agreements eventually confirmed by the fingerprints of both sides. It was widely agreed that this process was much more respected than was the case with governmental solutions elsewhere, because it had been negotiated by the villagers themselves. There is no suggestion in the meeting notes of the farmers or other interest groups organizing themselves or acting collectively. Rather, as Zhou (1993) has previously noted, the affected individuals adopted behaviors that allowed the $\mathrm{YSH}$ to hold collective village meetings that were suitable for establishing solutions that met individual aspirations. The group of seven villagers chosen by the YSH to be responsible for running the program included senior Party members, reputable elders of the village, previous leaders of the Village, and a villager who did not participate in the program. All decisions about the program, such as the survey of the total construction land area, new house planning, dismantling the old houses and building and allocating the new houses, were made by the special group and 
implemented by the Village Committee and all villagers. All the expenses of the program were also controlled by the Group members. From 2011 to 2013, about 37 official group meetings were held, with meeting records, and fingerprints of participants.

It was apparent that the Group knew well the risks and problems that they would encounter, and that they had the backing of the villagers and were creative enough to overcome them. This was particularly the case when the company withdrew; not only did the Group secure new funds, but the funder agreed to pay in advance for their CURCL credits, at a low price. However, the investment was smaller than that originally agreed with the private company, which meant that villagers had to bear more of the costs, in the process increasing their sense of injustice. Despite the wish to work collectively, some villagers were not satisfied with the outcome, meaning that the Group had to find consensus in order to proceed with the program. Meeting Records from 2011.12.10 give a flavor of what happened:

Song (female farmer): Why do we have to pay 3,000 yuan per capita and then 1200 per square meter? Yao (committee member): The 1200 yuan per square meter was for the additional space available for each family besides the share of 35 square meters per capita, and the 3000 yuan per capita was for participating the program [as we didn't have enough investment.] Wang (male farmer): How about the potential benefits of lands taken for the new housing site and those reclaimed for farming, when they are expropriated by the government in the future? Yao: The benefits for lands and houses expropriated by the government in the future will be redistributed at the village level.

Lv (male): Where can we store our tools when waiting for the new housing?

Yao: You have to deal with it yourselves.

In other villages where private companies were successful, participants did not pay extra money per capita. However, even though some of the Lianghe villagers were not happy with it, they still participated in the program, and supported the collective 
decisions.

A major risk which troubled the local bureau of land and resources with respect to the implementation of CURCL generally was that individual farmers did not respect the contracts. For example, there were cases in some villages where farmers got a new house but did not dismantle the old one, as their contract required. However, it was very difficult for the government to monitor the situation, with the local officials relying on the deposits paid as a means of ensuring compliance. In Lianghe Village the YSH agreed to set strict rules to avoid the risk:

... All participants should dismantle the old house soon after signing the contracts. All the housing lands should be reclaimed as farmland for food crops, and no tree planting is allowed. (Meeting records of 2011.12.14)

One of the villagers refused to demolish his old house. After the new houses were built he tried belatedly to join the program by asking his relative - an officer in the Provincial government - to call the Village Committee Leader, Yao. The village committee rejected his approach:

If you didn't dismantle the old house, then you can't get the new one ... All the villagers are watching us. If we start to give in, then there is nothing we can do in the future. (Yao, female)

Despite protests from the farmer, the remaining villagers strongly supported the decision, as the group and the village committee were protecting their common interests, even where it meant that they would be inconvenienced or would otherwise lose out. Here there was a clear collective approach to the issue, involving many villagers and the $\mathrm{YSH}$, although there is no evidence that there was any specific organization of the collective. Rather, the strong social identity of the villagers, allied to their widely perceived injustice, enabled them to support strong decisions. In this case they had the efficacy necessary to act collectively without the need for organization. In Zhou's (1993) terms, the convergent behavior of 'large numbers' of 
individuals provided a collective standpoint from which action could be taken in their (collective) name.

Membership of the village - and thus access to the benefits of the CURCL scheme was in many cases a difficult question that inspired much conflict. This was largely because of the Hukou (household registration) system (Cheng and Selden, 1994; Chan and Zhang, 1999; Song 2014, Andreas and Zhan 2016). Unlike many population registration systems, the Hukou system was designed to regulate population distribution as well as providing a range of population data. Indeed, Chan and Zhang (1999) have described the system as one of the major tools of social control employed by the state. This meant that some people who had left the village years before could still claim residence while others - outsiders who had married local farmers, for example - often could not, unless their Hukou had transferred with them. Not only did this system regulate the social status of the villagers (Cheng and Selden, 1994), but it also meant that decisions made about the allocation of land and housing had substantial financial impacts. In Lianghe Village, the total amount of benefit was fixed, with the decision about how to divide it among the village members negotiated by the YSH. Following extensive consultation the YSH produced a set of rules for the allocation of the benefit, which was approved by the village committee. This meant that the village had its own rules, generated through a form of collective action. The rules included provision for future population increases, protection for incomers who lived in the village but did not have the correct Hukou, and recognition of continuing residence for those who were away in higher education and military service.

One area of potential conflict that related centrally to the ownership of Hukou was the allocation of the new houses. In Lianghe Village the YSH approached this by making the process as fair and transparent as possible:

Those whose houses or lands are taken by the new housing site have the priority to choose a new house. (Meeting records of 2011.4.16 /2011.4.28) (Village group 11)/ (Village group 10)

All participants should take 2 trees before moving into the new house (for the community greening). Those with houses or lands taken by the new 
housing site choose the new houses first. Others choose the new house strictly by lottery. (Meeting records of 2011.12.10)

In order to ensure the fairness (of house allocation), an YSH member should be chosen every day to finalize the process. All the participants should be checked whether they fulfilled the requirement or not. The lottery used on April 30 should be designed and packed together by village representatives. The results of the lottery should be announced immediately. (Meeting records of 2013.4.20.)

As the records suggest, the allocation of the new houses was mainly done by lottery, with the process video-recorded and journalists invited to make sure that the process was transparent and fair. By doing this, Lianghe Village gained strong support from the villagers, including those who did not participate in the program.

The Group also kept the costs down, which was especially important given the limited investment. According to Yao, the overall construction cost of the new housing was only half of the one run by the local government. A bidding system for the materials and engineering services was already well established because the Group members were familiar with local merchants, and they spent lots of time doing market investigation voluntarily.

Another advantage of the approach deployed in Lianghe Village was the level and precision of internal and external monitoring. As the Group in charge of the program, all decisions were recorded with fingerprints, and meetings were documented as well as being open to the villagers. The Group also shared the responsibility to ensure that the quality of the housing was good, by monitoring the construction site both day and night. It was also in the farmers' interests to do the monitoring effectively because their old houses had been demolished before they could move into their new homes meaning that they were in temporary accommodation. They therefore had a strong incentive to make sure that the construction was undertaken properly and to time. 
The most obvious advantage of this form of collective action at the local level was that the Group managed to implement the program, even with the limited funding available and some villagers unhappy at the settlement that had been achieved. The Group's internal problem solving mechanism was the key to effective bottom-up decision making. One of the controversies was about the compensation for lands taken up by the new housing site. Due to the shortage of money for the program, the compensation rate for lands taken was lower than in other villages, at about 36,000 yuan per mu $(2,400$ yuan per hectare). Villagers found out that it was nearly double this in nearby towns, where the program was run by companies. However, the village committee could not fulfill their demands for additional compensation. Thus meetings were held frequently to negotiate a solution:

From meeting records of 2011.04.15 and 16

(on the site occupied by the new housing, negotiation meetings with the village group 11 )

Li (1): (As a member of group 11) I agree with the decision about the new housing site on village group 11 . We need to clarify to members that we should appreciate the precious opportunity we now have. It's a good thing and beneficial to all of us. For my kiwi fruit lands that have been taken, some compensation for the cost is enough for me.

Huang (1): the compensation for land was 15 thousand yuan per mu when the pork price was 2-3 yuan per jin $(500 \mathrm{~g})$. Now the pork price has increased a lot to $11-12$ yuan per jin ( $500 \mathrm{~g})$, while the compensation is only 30 thousand yuan per mu. It is really unsound... if the lands are taken, I don't have any lands left.

Li (2): The compensation is really low indeed.

Huang (2): Someone might find the compensation too low no matter what standard it is. ... It's quite possible that the program can't afford it finally.

Yao: If you want to continue farming, it is possible to exchange lands for you. [...] We had better think about the common interest of the village. The investment for the new housing site is about 100 million yuan. How long does it take the whole village to earn so much money?

After days of negotiation, they managed to reach agreement: the compensation 
standard remained unchanged, while there were more benefits for those whose land was taken. For example, they were offered living cost subsidies at 140 yuan per month per capita and they had the priority on choosing the new housing. If there were lands taken up by the government in the future, the benefit would be redistributed at the Village level. Most of those with strong opposing opinions were persuaded and had their finger printed (meeting records of 2011.04.16). It was commonly understood that this level of success was due to the work of the village committee.

However, there were two households who didn't accept the deal. One insisted on compensation of at least 60,000 yuan per mu, because there were kiwifruit trees on the land with 30,000 yuan per mu output annually; the other was trying to blackmail the village, asking for compensation of 3 new houses for 1 old house (used for pig raising) taken. This owner lived in Chengdu City and refused to budge after all kinds of negotiations.

I was with the YSH that all villagers should be treated equal, or the consensus with other villagers we had achieved before would be dismantled, and it was impossible to continue working afterwards. Thus we all finally agreed to give them up. Now you can see the kiwi fruit fields in the new community, also the shabby pig raising house there. (Yao, female)

With the support of the Village Committee, the Group set up rules without exception, through which the Village Committee gained support from the local town government. This process enhanced the trust of villagers toward the Group and the village cadres. With strong involvement of the villagers during the whole process, and the work done by the Group, the program went smoothly with high levels of satisfaction, even though the compensation standard was lower than expected and the private cost was higher than other villages. For example:

At first it was said that the price of the credits was 300,000 yuan per mu, 
and villagers didn't need to pay for the new house, even the decoration. Later the price dropped down to 180,000 per mu, not enough to support the new house building. ... finally villagers had to pay 3,000 yuan per capita for the new house. (Wang, male)

Nevertheless, Wang claimed that about 90\% villagers supported the program because they would get a new house for not much money. Wang didn't participate in the program (because his house was not large enough on the per capita base and it was just redecorated after an earthquake of 2008), but he had about 1 mu land taken for the new housing site with low compensation standard. According to his observation, Wang agreed that the program was a rare opportunity for the farmers and village and the collective was doing a good job, so he agreed with the village when it came to the negotiations. Other non-participants had similar reasons to Wang, while some people were unwilling to dismantle their old house that had been passed down by generations. Some farmers were also influenced by their expectation of future incomes:

Some [farmers] are doing pig farming at home, which is not allowed in the new community. They would lose the income if they participate. I gave up pig farming in order to participate in the program. I used to raise 200 pigs, and the annual loss is about 50,000-60,000 yuan. ... Others didn't participate because the new housing site is too far from their farmland. (Ni, female)

There were some complaints from the villagers about the new community life. The most significant one concerned the prohibition against keeping animals, given that animal breeding used to be a cornerstone of the farming community. The villagers also emphasized the cost of losing jobs and incomes after moving into the new community. The Group and the YSH worked together with the Village Committee and decided to support the demands of the villagers by submitting an application to government for a centralized facility for animal breeding, with a suitable pollution control mechanism. 
In total, the Group spent days and nights on the program without payment, while the village cadres were responsible for a lot of voluntary work that took up their private time. For example, after the construction of the new community, it required four security guards and four cleaners to care for it. However, the village could not afford the salaries at that time. Thus the village cadres took turns at cleaning the public community spaces. The villagers welcomed the work of the Group and the village cadres, and volunteered to participate themselves. They also agreed that, after obtaining the full price of the land credits, part of the money should be paid as an allowance to the Group and the village cadres. Again this agreement was achieved without the need for formalized collective action. Rather, because the YSH had organized an open and transparent process, the behaviors and attitudes of the individual villagers were largely consistent, meaning that the 'subordinate society' described by Zhou (1993) had become, in Lianghe Village, a powerful collective that supported actions that were not always in the interests of individuals, but which were judged to benefit the collective.

\section{Discussion and conclusions}

Despite participation in the CURCL policy being voluntary and despite many villagers gaining better housing as a result (Yep and Forrest, 2016), most commentaries have been largely critical of the land transfer process, with the farmers themselves portrayed in the main as powerless and with little social capital to defend their position (Long, et al, 2012; Huang, et al, 2013). This disempowerment has been attributed to defects in the CURCL policy which, it is argued, has provided strong incentives for local governments to put their own financial self-interest ahead of local people (Tang, et al, 2012). This may well be the case, whether the local governments are directly involved in the implementation of the policy, or rely on third party implementation via investment companies. What is not clear, however, is how far this is intrinsic to the CURCL policy itself (ie that it relies on power and value imbalances 
to create the financial incentives for land redistribution), or how far it is a function of the ways in which it has been implemented. For many commentators it is seemingly the former: that top-down policies of this sort necessarily subjugate individual claims in favor of broader welfare goals. Indeed, it seems that this view has been justified by claims that many farmers are better off from participating in CURCL schemes: they may have been separated from their land, with their livelihoods and food security diminished, but they live in good housing in new communities (Chen, 2009; Zhou, 2010; Huang, et al, 2013; Jiang, et al, 2015). Even the more doubtful commentators such as Siciliano (2012) steer away from political arguments to concentrate on the social and environmental costs of relocation and separation from the land.

With reference to work on collective action (van Zomeren, et al, 2012) we have not been convinced by these arguments - either that the CURCL policy is necessarily only a top-down intervention, or that economic efficiency and the maximization of financial surpluses are intrinsic to its implementation. Rather, we have sought to argue that top-down policies such as CURCL do not necessarily have to be implemented from the top down, while we have also argued that those who are most affected by such policies usually possess some agency that they can deploy through collective action, even if the political climate is not conducive to these tactics (see Liu, Z., et al, 2016). However, in contrast to conventional understandings of farmers under threat participating in organized and purposive collective action (Wanyama, et al, 2014), we have witnessed the apparent opposite: lots of individual people whose behaviors converged in ways that indicate a collective sensibility, if not precisely collective action. This is very much the approach to collective action described by Zhou (1993); action that is collective in character but individual in practice and intent.

While suggesting that self-interest should dominate in the absence of purposive collection action, the evidence from Lianghe Village is that social networks and hierarchies can still produce collective responses, even in adverse circumstances. Thus, even a policy which demands that people leave their family homes for little 
compensation and an uncertain future can still be implemented effectively from the bottom up; and even those who stand to lose the most are capable of acting individually in the interests of the collective, even when their personal interests are likely to be compromised. It may well be that Lianghe Village is atypical; it has certainly not seen the levels of dissent and violence reported on occasion elsewhere (Huang, et al, 2013) and it has had a strong take-up of the CURCL program. One reason for this, and the reason that we chose it as a case study, was that the village operated its own program, without substantial outside intervention. While still heavily influenced by a small insider group, the village community does seem to have responded to the legitimization (efficacy) of collective action that has reportedly been missing from the implementation of similar schemes elsewhere (Tang, et al, 2012). Indeed, it seems that all three key elements for the instigation of collective action were present, in terms of injustice (felt keenly by many farmers), social identity (that Lianghe villagers are able to act in the interests of the collective) and - when the private company dropped out and the village committee took control of policy implementation - efficacy (see van Zomeren, et al, 2012).

This brings us back to the aim of our paper, which was about the impacts of CURCL on farmers and the extent to which the outcomes of these impacts have been determined by the ability of the farmers to participate in effective collective action. The bottom line, in Lianghe Village as elsewhere, has been that many farmers have been displaced, often from inherited family houses to new high-rise apartments. For some, this has been hard, particularly when associated with having to give up their livestock and poultry. For those who have felt unable to continue farming there have also been financial worries about whether there are going to be jobs available for them; they may have got a new home at a fraction of the cost of building it, but they have also lost their livelihood as well as their way of living. There was also at least one farmer who kept his land, against the wider interest, because of its economic viability, reflecting Jiang, et al's (2016) observation that many land policies fail to appreciate that different farmers face different economic environments. Yet, in 
contrast to many stories from other villages, there does not seem to have been the level of tension, lies and deceptions that other villages reportedly experienced. Indeed, the villagers made a point of highlighting the behaviors that underlie their social identity: that they trusted one-another and had not gone in for tactics to increase their personal gains at the expense of others. It was also accepted that not everyone would join the program, and that this was not a source of disappointment or dispute.

One factor that may help explain the situation in Lianghe Village is that there was more emphasis than in other villages on the mechanics of implementing the policy. This allowed individuals to understand the wider implications of the policy and to act in ways that they knew would elide with the behaviors of others. In other words the actions of the YSH created the conditions in which individual behaviors converged into bottom-up collective action. This engagement with the detail of the CURCL policy may well have meant that there was little consideration of wider issues such as food production and security. Indeed, despite concerns for food security being part of many Chinese land transfer programs (Fang, et al, 2016), no one mentioned concerns about where their food would come from, nor what would happen to their land. Indeed, apart from some isolated questions about interim arrangements for storing tools, very little mention was made of the future of farming in the village. This is not to say that it was not important, but somehow most of the interviewees seem to have accepted that the program would be implemented and that their farms were worth less than the opportunity to move into a new apartment in the new village center.

Our remaining question is to what extent the findings from Lianghe Village were influenced by the villagers' experience of the implementation of the program, and the extent to which this was a result of decisions made by the village committee to foster collective action. What is clear is that the village committee took a brave decision in taking on program implementation after the investment company pulled out, and that 
many of the villagers respected them for this. To some extent - although probably not viewed in this way at the time - this heightened the sense of injustice that brought the community together, particularly when they discovered that the financial deals that they would get were not as good as those in neighboring villages. There is also no doubt from the interviews that the villagers had a shared identity - as fair-minded citizens - although whether this was as a result of the village committee's actions, or was already present, is unclear. What is certain, however, is that in taking the steps that it did, the village committee gave efficacy to the notion that the community would take action and that everyone would be included in decision making and policy implementation.

This was clearly a success. There were many stories of long meetings and difficult conversations, all told with a sense of pride and achievement, and all sealed with fingerprints at the end. There was no sense in any of the interviews that people had been marginalized or excluded, with even those who did not participate in the program claiming that it had been a fair and positive process. It certainly seems to have helped that the implementation group were known to the villagers and seem to have been held in high esteem. This meant that even where families stood to lose out, there was a connection to the community and collective decisions and action were seen to be more important than individual preferences or benefits. This should not detract, however, from the way that the implementation group organized and carried out its work. There is no doubt that its willingness to meet and discuss issues helped maintain the momentum of the process, while its ability to help the villagers secure better deals, whether over the size of their new homes, the qualification for scheme membership or the provision of a facility for keeping poultry, meant that the villagers had trust in the people and the process.

In their work, Tang, et al (2012) call for the revision of the CURCL policy to include provision for 'smart use' particularly in defining what constitutes the public interest and how this should be protected in cases where the expropriation of land is 
required. While their concerns are primarily about limiting the spatial encroachment of cities on farmland, this same call echoes very much at the local scale: that steps need to be taken to ensure that local interests are considered and protected during implementation. If this cannot be via local government, because of conflicts between its economic and social responsibilities, our research indicates that it can be undertaken in a collective way that recognizes and addresses the individual concerns and behaviors of all those affected.

That this happened in Lianghe Village is no coincidence: it was where the conventional top-down approach failed and was replaced by a more localized, democratic and, ultimately, collective approach. This is very much the contribution that this work has made to the current debates. It is not important in itself whether Lianghe Village represents an isolated or special case; what matters is that, even in the face of a potentially devastating top-down policy, the behaviors of local people coalesced in a form of individualized collective action that was legitimized by the actions of the village committee. While many commentators may comment on the lack of stakeholder engagement in the implementation of other CURCL schemes, the findings from Lianghe Village offer an opposing picture in which the community was intimately involved. This suggests that we should not rush to condemn policies such as CURCL for being remote or biased in favor of certain outcomes. Rather, we should recognize that, given suitable conditions, even marginalized people have agency that they can mobilize through individual behaviors that, together, amount to collective action.

\section{References}

Andreas, J. and Zhan, S. (2016) Hukou and land: market reform and rural displacement in China. The Journal of Peasant Studies 43(4): 798-827.

Bai, Y., Jiang, B., Wang, M., Li, H., Alatalo, J.M. and Huang, S. (2016) New ecological redline policy (ERP) to secure ecosystem services in China. Land Use Policy 55: 348-351. 
Bosco, F.J. (2001) Place, space, networks, and the sustainability of collective action: the Madres de Plaza de Mayo. Global Networks 1(4): 307-329.

Brown, D.L. and Shucksmith, M. (2016) A new lens for examining rural change. European Countryside 2. 2016 · p. 183-188. DOI: 10.1515/euco-2016-0015.

Chan, K.W. and Zhang, L. (1999) The Hukou System and rural-urban migration in China: processes and changes. The China Quarterly 160: 818-885.

Chen, X. (2009) Review of China's agricultural and rural development: policy changes and current issues. China Agricultural Economic Review 1(2): 121 - 135.

Cheng, T. and Selden, M. (1994) The origins and social consequences of China's Hukou System. The China Quarterly 139: 644-668.

Dou, J.L., Zhang, J.L. Zhang, F.R., Wang, N., Yang, H. and Lu, J. (2008) Ecological effect evaluation of rural residential area improvement. Natural Resource Economics of China 5: 38-40.

Fang, Y.-g., Shi, K-j. and Niu, C-c. (2016) A comparison of the means and ends of rural construction land consolidation: case studies of villagers' attitudes and behaviours in Changchun City, Jilin province, China. Journal of Rural Studies http://dx.doi.org/10.1016/j.jrurstud.2016.04.007.

Friedmann, J. (2006) Four theses in the study of China's urbanization. International Journal of Urban and Regional Research 30(2): 440-451.

Gilbert, M. (1989) On social facts. London \& New York: Routledge.

Gilbert, M. (2006) Rationality in collective action. Philosophy of the Social Sciences 36 (1): 3-17.

He, Y., Yang, W.R., Guo, R., Zhao, D., 2014. Designation and management of urbanecological redline. Beijing Plan. Rev. 2, 21-25.

Huang, C., Deng, L., Gao, X., Luo, Y., Zhang, S. and Liu, L. (2013) Rural housing land consolidation and transformation of rural villages under the "Coordinating Urban and Rural Construction Land" Policy: a case of Chengdu City, China. Low Carbon Economy 4: 95-103.

Jiang, G., He, X., Qu, Y., Zhang, R. and Meng, Y. (2016) Functional evolution of rural housing land: a comparative analysis across four typical areas representing different stages of industrialization in China. Land Use Policy 57: 645-654. 
Jiang, L., Seto, K.C. and Bai, J. (2015) Urban economic development, changes in food consumption patterns and land requirements for food production in China. China Agricultural Economic Review 7(2): 240 - 261.

Jin, X., Zhang, Z., Wu, X., Xiang, X., Sun, W., Bai, Q. and Zhou, Y. (2016) Coordination of land exploitation, exploitable farmland reserves and national planning in China. Land Use Policy 57: 682-693.

Lauckner, H., Paterson, M. and Krupa, T. (2012) Using constructivist case study methodology to understand community development processes: proposed methodological questions to guide the research process. The Qualitative Report 2012, vol 17, Article 25, pp. 1-22.

Li, J. (2013) What causes China's property boom? Property Management 31(1): 421.

Li, Y., Liu, Y., Long, H. and Cui, W. (2014) Community-based rural residential land consolidation and allocation can help to revitalize hollowed villages in traditional agricultural areas of China: evidence from Dancheng County, Henan Province. Land Use Policy 39: 188-198.

Li, Y., Westlund, H., Zheng, X. and Liu, Y. (2016) Bottom-up initiatives and revival in the face of rural decline: case studies from China and Sweden. Journal of Rural Studies http://dx.doi.org/10.1016/j.jrurstud.2016.07.004.

Liang, C., Penghui, J., Wei, C., Manchun, L., Liyan, W., Yuan, G., Yuzhe, P., Nan, X., Yuewei, D. and Qiuhao, H. (2015) Farmland protection policies and rapid urbanization in China: a case study for Changzhou City. Land Use Policy 48: 552566.

Lin, G.C.S. and Ho, S.P.S. (2003) China's land resources and land-use change: insights from the 1996 land survey. Land Use Policy 20: 87-107.

Liu, P., Ravenscroft, N., 2016. Collective action in China's recent collective forestry property rights reform. Land Use Policy 59, 402-411.

Liu, P., Ravenscroft, N., Harder, M.K. and Dai, X. (2016) The knowledge cultures of changing farming practices in a water town of the Southern Yangtze Valley, China. Agriculture and Human Values 33(2): 291-304.

Liu, Z., Müller, M., Rommel, J. and Feng, S. (2016) Community-based agricultural land consolidation and local elites: survey evidence from China. Journal of Rural Studies (2016), http://dx.doi.org/10.1016/j.jrurstud.2016.06.021. 
Long, H.L., Li, Y., Liu, Y., Woods, M. and Zou, J. (2012) Accelerated restructuring in rural China fueled by 'increasing vs. decreasing balance' land-use policy for dealing with hollowed villages. Land Use Policy 29(1): 11-22.

Long, H., Liu, Y., Wu, X. and Dong, G. (2009) Spatio-temporal dynamic patterns of farmland and rural settlements in Su-Xi-Chang region: Implications for building a new countryside in coastal China. Land Use Policy 26: 322-333.

Long, H.L., Tang, G.P., Li, X.B. and Heilig, G.K. (2007) Socio-economic driving forces of land-use change in Kunshan, the Yangtze River Delta Economic Area of China. Journal of Environmental Management 83(3): 351-364.

Long, H., Zou, J., Pykett, J. and Li, Y. (2011) Analysis of rural transformation development in China since the turn of the new millennium. Applied Geography 31: 1094-1105.

Lu, Y., Ma, Z., Zhang, L., Fu, B. and Gao, G. (2012) Redlines for the greening of China. Environmental Science \& Policy 33: 346-353.

Nolan, P. (1988) The Political Economy of Collective Farms: An Analysis of China's Post-Mao Rural Reforms. Cambridge: Policy Press.

O'Brien, K.J. and Li, L. (2006) Rightful resistance in rural China. Cambridge: Cambridge University Press.

Oliver, P.E. (1993) Formal models of collective action. Annual Review of Sociology 19: $271-300$.

Olson. M. (1965) The logic of collective action. Public goods and the theory of groups. Cambridge, MA: Harvard University Press.

Ostrom, E. (1990) Governing the commons: the evolution of institutions for collective action. Cambridge: Cambridge University Press.

Panelli, R. (2004) Social geographies: from difference to action. London: Sage.

Qin, H. and Liao, T.F. (2016) Labor out-migration and agricultural change in rural China: a systematic review and meta-analysis. Journal of Rural Studies http://dx.doi.org/10.1016/j.jrurstud.2016.06.020.

Siciliano, G. (2012) Urbanization strategies, rural development and land use changes in China: A multiple-level integrated assessment. Land Use Policy 29: 165-178. 
Simpson, B. and Macy, M.W. (2004) Power, identity, and collective action in social exchange. Social Forces 82(4): 1373-1409.

Skinner, M.W., Kuhn, R.G. and Joseph, A.E. (2001) Agricultural land protection in China: a case study of local governance in Zhejiang Province. Land Use Policy 18: 329-340.

Song, Y. (2014) What should economists know about the current Chinese hukou system? China Economic Review 29: 200-212.

Tang, Y., Mason, R.J. and Sun, P. (2012) Interest distribution in the process of coordination of urban and rural construction land in China. Habitat International 36: 388-395.

van Zomeren, M., Postmes, T. and Spears, R. (2012) On conviction's collective consequences: Integrating moral conviction with the social identity model of collective action. British Journal of Social Psychology 51(1): 52-71.

Wanyama, F., Poulton, C., Markelova, H., Dutilly, C., Hendrickse, G., Bijman, J., Francesconi, G.N., Bernard, T., Cook, M., Badiane, O. and Wouterse, F. (2014) Collective action among African smallholders. Trends and lessons for future development strategies. Thematic Research Note 05. Dakar: International Food Policy research Institute - West and Central Africa Office.

Wu, X.L. (2011) The experience and inspiration of linking the increase and decrease of the land for construction use in both urban and rural areas in Chengdu City. Soft Science 25(5): 99-101.

Xu, Y., Tang, B. and Chan, E.H.W. (2011) State-led land requisition and transformation of rural villages in transitional China. Habitat International 35: 57-65.

Yang, H. and Li, X. (2000) Cultivated land and food supply in China. Land Use Policy 17: 73-88.

Yep, R., and Forrest, R. (2016) Elevating the peasants into high-rise apartments: the land bill system in Chongqing as a solution for land conflicts in China? Journal of Rural Studies http://dx.doi.org/10.1016/j.jurstud.2016.07.017.

Yin, R.K. (2009) Case study design: research and methods. London: Sage.

Zhou, X. (1993) Unorganized interests and collective action in Communist China. American Sociological Review 58: 54-73.

Zhou, Z. (2010) Achieving food security in China: past three decades and beyond. 
China Agricultural Economic Review 2(3): 251 - 275. 